\title{
EL DEFENSOR DEL PUEBLO EN CENTROAMÉRICA. ANÁLISIS COMPARADO*
}

\author{
CAYETANO NÚÑEZ RIVERO \\ Profesor Titular de Derecho Constitucional \\ UNED
}

CELIA FERNÁNDEZ ALLER

Profesora Titular Interina de Derecho Constitucional

Universidad Politécnica de Madrid

\author{
SUMARIO \\ I. Antecedentes. \\ II. Naturaleza jurídica y características. \\ III. Organización. \\ IV. Funciones. \\ V. Principales retos de la institución.
}

\section{ANTECEDENTES}

La primera figura constitucionalizada del Ombudsman aparece en la Carta Magna sueca de 1809, mediante este texto se crea el Justitie Ombudsman. La creación de esta figura es consecuencia de la pretensión de la institución parlamentaria de controlar el cumplimiento de las leyes por parte de jueces y funcionarios; con la creación de este comisionado del Parlamento se pretendía hacer más ágil dicho control, especialmente en los periodos en los que la Cámara Legislativa no se encontraba reunida ${ }^{1}$. La figura se reforzaría en los inicios del siguiente siglo mediante la creación del Militie Ombudsman².

* Este trabajo se ha elaborado en el marco del Proyecto de Investigación del Ministerio de Ciencia e Innovación DER 2009-10375 sobre “Constitución y Globalización. Transformaciones del Estado Constitucional y constitucionalización de espacios supranacionales".

1 En la temprana fecha en la que se crea esta figura, todavía está consolidándose el concepto de Monarquía Constitucional, caracterizándose por las grandes atribuciones del Rey en materia ejecutiva y control de la Administración; así mismo, el Parlamento sólo se reunía en determinados periodos de sesiones, de carácter corto y discontinuo.

2 En 1915 se crea esta institución para el control de la Administración militar; en 1969 se unificarían estas instituciones. 
El ejemplo sueco será seguido por otros países escandinavos, así Finlandia creará la figura en 1919, Noruega en 1952 y Dinamarca la incorporará a su texto constitucional en 1953; en los siguientes años figuras similares serán creadas en la República Federal Alemana, Reino Unido, Canadá, Nueva Zelanda etc.

Los países iberoamericanos, después de atravesar un periodo histórico ciertamente difícil, colmado de enfrentamientos y dictaduras militares, marcado por las tensiones extremas de la guerra fría, iniciaron en su mayor parte, desde mediados de los años ochenta, un proceso de estabilización democrática. Posiblemente siguiendo el ejemplo de la transición española, en donde la Constitución de 1978 crea la figura del Defensor del Pueblo, algunas de las nuevas constituciones democráticas iberoamericanas acogieron también la figura del Ombudsman, bajo diversas denominaciones. En aquellos países en los que no se hizo uso de la correspondiente referencia constitucional se optó, alternativamente, por promulgar una ley de creación del Defensor. Pero una característica común a todas las recién nacidas instituciones fue la de configurarlas como entidades de protección y promoción de los Derechos Humanos $^{3}$.

De esta forma, otras normas constitucionales la crean en Guatemala en 1985, en El Salvador en 1991, y en Méjico en 1992. Una ley ordinaria en 1992 en Costa Rica. Finalmente, Honduras aprueba su creación por disposición gubernativa en 1993.

La mayor parte de los países iberoamericanos ${ }^{4}$ adoptaron la denominación de Defensor o Defensoría del Pueblo. Es el caso de Argentina, Paraguay, Colombia, Venezuela, Bolivia, Perú, Panamá y Ecuador. En Costa Rica, uno de los primeros países en poner en marcha la iniciativa, la institución fue bautizada como Defensoría de los Habitantes. Por otro lado, los países de Centroamérica, en general, decidieron resaltar en su denominación el objetivo de salvaguarda de los derechos universales y, así, los altos comisionados parlamentarios correspondientes se denominaron Procuradores de los Derechos Humanos, en El Salvador, Guatemala y Nicaragua. Posiblemente Honduras y, sobre todo, México representan los casos más diferenciados del modelo, y no sólo por la denominación escogida. En estos países se encuentran constituidas unas Comisiones Nacionales de Derechos Humanos, cuya peculiaridad es que nacieron por virtud de sendos decretos presidenciales. En la actualidad, corresponde a los Parlamentos nacionales la elección de los Presidentes de dichas comisiones que reúnen las características propias de las defensorías del pueblo; de hecho, las instituciones de estos países participan plenamente y se

3 GIL ROBLES Y ALVARO GIL DELGADO, A.: El Defensor del Pueblo y su impacto en España y América Latina. Antología básica del Curso Interdisciplinario sobre Derechos Humanos. San José de Costa Rica, 1994, pág. 2.

4 Conferencia del Defensor del Pueblo, Excmo. Sr. Don Enrique Mugica Herzog, en la XIX edición del curso Postgrado en Derecho Constitucional Facultad de Derecho. Universidad de Salamanca Salamanca, 10 de enero 2006. pág. 16. 
muestran muy activas en el impulso internacional y el apoyo a las iniciativas defensoriales en todo el mundo.

Algunos antecedentes de los Procuradores latinoamericanos ${ }^{5}$ : Ombudsman escandinavo, Sahib-al-Mazalin (juez nombrado por el sultán), Justicia Mayor de Aragón, Protector de los indios (Bartolomé de las Casas)...

\section{NATURALEZA JURÍDICA Y CARACTERÍSTICAS}

La forma en la que se configura la figura del Defensor del Pueblo en España en 1978 es la que predomina en toda Latinoamérica y le ha dado sus características especiales. La definición del Ombudsman como órgano de control de la Administración, mediador, promotor de reformas, se extiende para incluir la defensa y promoción de los derechos humanos. Aunque su función inicialmente no era ésta, en Latinoamérica se ha centrado de forma muy especial en la protección de los derechos humanos ${ }^{6}$.

El Ombudsman se configura como un mecanismo constitucional de potenciación de todos aquellos otros tradicionalmente establecidos en cualquier sociedad democrática, como los tribunales de justicia independientes o la fiscalización llevada a cabo por los Parlamentos. No pretende arrinconar o sustituir ninguna otra vía constitucional de control, sino reforzar las ya históricamente existentes.

Todos los aspectos comunes relativos a la composición, la organización y el funcionamiento de los distintos Ombudsman de Centroamérica reflejan la intención de resaltar su característica fundamental de independencia. La designación por mayoría cualificada en las Cámaras legislativas nacionales y la conformidad de éstas con el nombramiento de los Adjuntos que auxilian al Defensor; las prerrogativas del titular de la Institución, en especial las de no sujeción a mandato imperativo, inviolabilidad, inmunidad y fuero especial, o el estricto régimen de incompatibilidades, son otras tantas señales del alto margen de autonomía de esta institución.

La actuación independiente respecto del poder ejecutivo se expresa bien, entre otras cosas, por el deber legal de colaboración de la Administración con la institución defensorial. En la mayoría de los países de nuestro estudio está previsto un procedimiento sancionador para los casos de desobediencia al Defensor o Procurador de los Derechos Humanos. En muchos de ellos, como ocurre en España, esa actitud obstaculizadora puede acarrear consecuencias de orden penal, en virtud de la tipificación del delito de desobediencia. Por tal desobediencia puede entenderse cualquier acción u omisión de una autoridad o funcionario que dificulte la investigación iniciada por el

5 GIL ROBLES Y GIL-DELGADO, A.: «El Defensor del Pueblo y su impacto en España y América Latina". Revista de la Asociación Iberoamericana del Ombudsman. n. ${ }^{\circ}$ 3, 1994, pág. 65

6 MAIORANO, J.L.: "The Defensor del Pueblo en Latin America". Righting wrongs: the ombudsman in six continents. IOS Press, Amsterdam, 2000. pág. 263. 
Defensor, negándose a elaborar o dilatando indebidamente el envío de los informes, o impidiendo el acceso a los expedientes o documentación administrativa necesaria para tal investigación.

Pero la manifestación más importante de independencia del Defensor en el modelo iberoamericano - que lo diferencia de los modelos nórdicos y anglosajón - es la que se establece respecto del poder legislativo por el que es designado. Una prueba de esta independencia originaria es el hecho de que algunas instituciones defensoriales iberoamericanas poseen, de una u otra manera, una especial legitimación para impugnar directamente las leyes, o disposiciones con rango de ley que pudieran vulnerar el catálogo de derechos incluido en los textos constitucionales. En algunos casos, como El Salvador, el Procurador para la Defensa de los Derechos Humanos puede hacer propuestas legislativas cuando se trate la materia de Derechos Humanos. En otros, otorgan al Defensor la competencia de sugerir la ratificación o la firma de tratados sobre Derechos Humanos; es el caso de Venezuela o Perú. Con ello, se proporciona un mecanismo indirecto a los ciudadanos para intentar hacer valer sus inalienables derechos fundamentales frente a la acción político-legislativa. Como es de suponer, esta especial legitimación conferida a los Ombudsman aconseja utilizarla con carácter excepcional.

Las relaciones de los Ombudsman en la región centroamericana con los órganos legislativos deben ser únicamente, por tanto, de dependencia orgánica, en la medida en que son nombrados por ellos y de ellos reciben, en la mayoría de los casos, los recursos presupuestarios. La elección se realiza, generalmente, por una mayoría especialmente cualificada, circunstancia que amortigua la influencia de los partidos en la designación del titular, y por un periodo, generalmente, de cinco años. Además, no obedecen a mandato imperativo alguno, con lo que la autonomía funcional queda legalmente garantizada. La única obligación prevista para los defensores respecto a las cámaras legislativas que los han designado es la presentación de un informe anual en el que dan cuenta de su actividad y de las resoluciones adoptadas, y en el que se suelen destacar los obstáculos y trabas encontrados en el seguimiento de las investigaciones llevadas a cabo cerca de los distintos órganos administrativos.

La naturaleza jurídica del Ombudsman centroamericano, es, sin embargo, controvertida. Existen fuentes muy autorizadas que denuncian falta de autonomía y de capacidad de influencia de estas instituciones ${ }^{7}$.

En este sentido, hay que recordar que los ombudsman han alcanzado madurez en los sistemas parlamentarios en los que el órgano que nombra a los defensores, el Parlamento, es también el de mayor poder político. Sin embargo, en los sistemas presidenciales de Centroamérica esto no es así, y dicha institución debe controlar a dos poderes "supuestamente independientes": el

7 UGGLA, F.: "The Ombudsman in Latin America". Journal of Latin American Studies. Vol. 36, n. ${ }^{\circ}$ 3, 2004, pág. 428 . 
poder judicial y el ejecutivo. Esto marca una diferencia importante en el trabajo y resoluciones de la institución en esta zona ${ }^{8}$.

Otro argumento en contra de la independencia de la institución en Centroamérica es el hecho de que el Ombudsman no tiene poderes coercitivos, no puede destituir funcionarios, juzgar a los violadores de los derechos humanos o cambiar decisiones burocráticas. Que sus resoluciones sean efectivas depende de que otros órganos estatales las acepten.

Con base en estas dos dimensiones tratadas (autonomía y capacidad de influencia), algunos autores ${ }^{9}$ clasifican los diferentes Ombudsman de la zona: El de Honduras tiene una capacidad de influencia aceptable, y suficiente autonomía; el de Guatemala tiene escasa capacidad de influencia y bastante autonomía; el Salvador ${ }^{10}$, sin embargo, tiene baja capacidad de influencia y escasa autonomía.

Como consecuencia de todo esto, podemos decir que la institución se encuentra en ocasiones un poco aislada, y no cuenta con una posición clara en la estructura estatal. El apoyo con que cuenta viene fundamentalmente de la sociedad y del extranjero, no de sus propias instituciones estatales. Si unimos a esto el bajo impacto de sus resoluciones, la conclusión es la falta de eficacia de la institución. Indudablemente, dicha eficacia dependerá a su vez de lo eficiente que sea el sistema judicial, de si los medios de comunicación están a su favor o no, así como de los procedimientos administrativos de control con que cuenten los sistemas jurídicos.

Algunos autores recuerdan que para que un Ombudsman pueda funcionar es exigencia ineludible que exista una verdadera democracia ${ }^{11}$. De ello podemos deducir las dudas acerca del papel de los Defensores en Centroamérica, dado que las democracias son incipientes, formales, y sin suficiente trayectoria ni experiencia.

Otros autores dudan de la posibilidad real de estas instituciones para llevar a cabo su complicada misión: González Casanova alude a sus «amplios y difíciles contenidos democratizadores ${ }^{12}$.

Es importante recordar la definición de la institución que hace Jorge Carpizo $^{13}$ : «el Ombudsman es un órgano del Estado, no del gobierno. Es decir, es un órgano público creado por la Constitución o por la ley para que se

8 KAARE S.: "Delegation and accountability in parlamentary democracies", European Journal of Political Research, vol. 37, n. ${ }^{\circ} 3,2000$

9 UGGLA, F.: op. cit., pág. 447.

10 A pesar de todo lo dicho, instituciones de la solvencia del IDHUCA mantienen su esperanza en la institución en los siguientes términos: "el reto será el de construir una institucionalidad fuerte que no dependa de los vaivenes políticos ni de la voluntad de quien llegue ahí, sino de una base organizativa y de personal que le marque el ritmo al titular y le facilite el cumplimiento de sus deberes". Citado por: Escobar Roca, Defensorias del Pueblo en Iberoamérica, Ed. Thomson Aranzadi, Pamplona, 2008, pág. 145.

11 GIL ROBLES, op. cit., pág. 55.

12 Teoría del Estado y Derecho Constitucional. Ed. Vicens Vives, Madrid, 1983, pág. 320.

13 Algunas reflexiones sobre el Ombudsman y los derechos humanos. Comisión Nacional de Derechos Humanos, 1992, pág. 14. 
cumpla funciones públicas y cuyas atribuciones están expresamente señaladas por la ley, pero no es ni forma parte de ningún órgano del gobierno. Su naturaleza es parecida a la de aquellos tribunales administrativos de última instancia, o sea que sus resoluciones ya no pueden ser recurridas...requiriendo que su titular sea de reconocida trayectoria en la promoción, educación y defensa de los derechos humanos, con amplios conocimientos en ese campo, de moralidad y competencia notorias".

\section{ORGANIZACIÓN}

Cada institución del Ombudsman cuenta con algunos rasgos diferenciadores en su modo de organización, composición y funcionamiento.

El Defensor del Pueblo español ${ }^{14}$, por ejemplo, se diferencia en algunas características del Ombudsman sueco. Y a su vez, los países centroamericanos objeto de nuestro análisis presentan sus propias peculiaridades.

\section{EL SALVADOR}

La institución se incorporó al sistema jurídico de El Salvador en los Acuerdos de $\mathrm{Paz}^{15}$ firmados en Méjico el 27 de abril de 1991 (vid. Acápite II,

14 La Ley Orgánica de 1981 expone en su Capítulo III sus prerrogativas e incompatibilidades. En cuanto a las primeras, se concretan en tres: Uno. El Defensor del Pueblo no estará sujeto a mandato imperativo alguno. No recibirá instrucciones de ninguna autoridad. Desempeñará sus funciones con autonomía y según su criterio. Es decir disfruta de autonomía. Dos. El Defensor del Pueblo gozará de inviolabilidad. No podrá ser detenido, expedientado, multado, perseguido o juzgado en razón a las opiniones que formule o a los actos que realice en el ejercicio de las competencias propias de su cargo. En los demás casos, y mientras permanezca en el ejercicio de sus funciones, el Defensor del Pueblo no podrá ser detenido ni retenido, sino en caso de flagrante delito, correspondiendo la decisión sobre su inculpación, prisión, procesamiento y juicio exclusivamente a la Sala de lo Penal del Tribunal Supremo. Es decir goza de inmunidad. Tres. No esta sujeto a mandato imperativo alguno, ni recibe instrucciones de ninguna autoridad, de modo semejante a los que sucede con los parlamentarios de las Cámaras. Correlativamente, el Defensor del pueblo está sometido también a un amplio catálogo de incompatibilidades (art. 7 LODP) que son: Uno. La condición de Defensor del Pueblo es incompatible con todo mandato representativo; con todo cargo político o actividad de propaganda política; con la permanencia en el servicio activo de cualquier Administración pública; con la afiliación a un partido político o el desempeño de funciones directivas en un partido político o en un sindicato, asociación o fundación, y con el empleo al servicio de los mismos; con el ejercicio de las carreras judicial y fiscal, y con cualquier actividad profesional, liberal, mercantil o laboral. Dos. el Defensor del Pueblo deberá cesar, dentro de los diez días siguientes a su nombramiento y antes de tomar posesión, en toda situación de incompatibilidad que pudiere afectarle, entendiéndose en caso contrario que no acepta el nombramiento. Tres. Si la incompatibilidad fuere sobrevenida una vez posesionado del cargo, se entenderá que renuncia al mismo en la fecha en que aquella se hubiere producido.

Para más información, vid. Pérez Calvo, A. «Rasgos esenciales del Defensor del Pueblo en $R e$ vista de Derecho Político, num. 11, 1981, UNED, pag. 67-81.

15 Acerca de la génesis y desarrollo de estos acuerdos en lo que se refiere a derechos humano, vid. Samayoa, S. El Salvador, la reforma pactada. San Salvador, Ed. UCA Editores, cap. 6. 2002. 
Sistema Judicial y Derechos Humanos). El 29 de abril del mismo año la Asamblea Legislativa aprobó las reformas constitucionales por las que se daba redacción a los actuales artículos 191 y 194, referentes al Procurador para la Defensa de los Derechos Humanos.

El Ombudsman salvadoreño no es un Alto Comisionado de las Cortes o un Comisionado Parlamentario, sino un órgano constitucional del Estado ${ }^{16}$, pues las reformas constitucionales lo ubicaron dentro del Ministerio Público, reiterando su independencia y autonomía frente a cualquier otro órgano estatal.

La Constitución, siguiendo las figuras del derecho comparado, ha instituido una figura unipersonal del Ombudsman, ya que es una persona en la que recae la autoridad y el prestigio para el desempeño de sus funciones.

En El Salvador, el procurador es elegido por la Asamblea Legislativa por mayoría cualificada de dos tercios de los diputados electos (art. 192 de la Constitución y 4 de la Ley). La duración del puesto es de tres años. Además de su Titular, la procuraduría está integrada por un Procurador Adjunto para la Defensa de los Derechos Humanos, los Procuradores Adjuntos para la Defensa de los Derechos del Niño, de la Mujer, de la tercera edad, del medio ambiente, todos ellos nombrados por el Procurador ${ }^{17}$.

Para ser elegido procurador es necesario: Ser salvadoreño por nacimiento, seglar, mayor de treinta cinco años, abogado de la República, de reconocida trayectoria en la promoción, educación y defensa de los derechos humanos. La ley recoge además una serie de cargos que no podrían ser procuradores de Derechos Humanos: funcionarios de elección popular, ministros o viceministros del Estado, magistrados de la Corte Suprema de Justicia, cónyuges o parientes hasta el cuarto grado de consanguinidad o segundo de afinidad, los integrantes de partidos políticos que desempeñan cargos en los órganos de dirección, los militares de profesión, y los que hubiesen sido condenados por violación de los derechos humanos.

Por lo que se refiere a la organización, el Procurador tiene libertad para elegir, nombrar y remover funcionarios y empleados de la Procuraduría.

La Procuraduría cuenta además con un Secretario General, delegados departamentales y locales, jefes de departamento y secciones y el personal técnico-administrativo que el Procurador convenga. Además, el Procurador puede nombrar personas o integrar comisiones para desempeñar una función específica de las señaladas por la Constitución y la Ley, inclusive puede designar a personas que no formen parte de la Procuraduría ${ }^{18}$.

16 SANDOVAL ROSALES, R. El Ombudsman, defensor de los derechos fundamentales. Ministerio de Justicia, ediciones Ultimo Decenio, San Salvador, 1995.

17 Vid. Un buen resumen de esta institución en BERTRAND GALINDO, TINETTI, KURI DE MENDOZA, ORELLANA. Manual de Derecho Constitucional, Ed. Centro de Investigación y Capacitación, San Salvador, 1992, cap. VII.

18 Para más información referente a la Procuraduría, véase al respecto, además de la Ley FERNÁNDEZ ALLER, C.: "Protección constitucional del amparo en El Salvador. Perspectiva comparada" Tesis Doctoral. UNED.. Madrid, 1998, pág. 252. 


\section{Costa RicA}

En Costa Rica, la Procuraduría de Derechos Humanos, creada como órgano de la Procuraduría General de la República en septiembre de 1982, cumplió funciones de defensa de derechos humanos. En la misma ley en que se creó la Procuraduría, se estableció la figura del Procurador del Consumidor. Posteriormente, se crearon el Defensor de Derechos Humanos para el Sistema Penitenciario, el Defensor de los Usuarios del Registro Nacional y el Defensor de los Derechos de los Refugiados. Este último órgano fue suprimido tiempo después.

Más adelante, en el seno del Ministerio de Justicia, se crearon las instancias específicas para velar por la tutela de los derechos de la mujer y de la infancia. Este proceso tomó fuerza con la aprobación de la Ley de Promoción de la Igualdad Social de la Mujer (Ley No. 7124) que vino para crear lo que se denominó la Defensoría General de los Derechos Humanos. Esta Defensoría se creó como un órgano adscrito al Ministerio de Justicia y tuvo como función la protección de los derechos humanos, por lo que se dividió en seis órganos específicos: Defensoría General; Defensoría de la Mujer; Defensoría de la Infancia; Defensoría del Consumidor; Defensoría de los Internos del Sistema Penitenciario y Defensoría del Usuario del Registro Nacional.

La organización, atribuciones y competencias de estas Defensorías fueron determinadas por reglamento ejecutivo. Aún cuando estas oficinas lograron alcanzar ciertos resultados de importancia, su vinculación jerárquica y presupuestaria con el Poder Ejecutivo, específicamente con el Ministerio de Justicia, significó una limitación para su trabajo.

La Defensoría de los Habitantes abrió sus puertas el 1 de octubre de 1993, después de que su primer Defensor, Rodrigo Alberto Carazo Zeledón, asumiera su cargo a partir del 22 de marzo de 1993. La primera Defensora Adjunta, Joyce Zurcher Blen de Carrillo, fue elegida el 28 de abril de 1993. Desde entonces, la Defensoría ha velado por el buen funcionamiento de los servicios del sector público, procurando que sus actos se ajusten a la moral, la justicia y a todo el ordenamiento jurídico. Además, le corresponde divulgar y promover los derechos de los habitantes de todo el territorio nacional.

El Defensor de los Habitantes es nombrado por la Asamblea Legislativa mediante mayoría absoluta de los diputados presentes y por un período de cuatro años, aunque puede ser reelegido por una vez para el mismo período. Los requisitos legales son: tener nacionalidad costarricense, encontrarse en el ejercicio de sus derechos civiles y políticos, mayor de 30 años y goce de solvencia moral y profesional.

En el cumplimiento de sus funciones y en el ejercicio de la potestad inspectora, el Defensor goza de ciertas prerrogativas: los órganos públicos tienen la obligación de colaborar y no podrán negarle el acceso a ningún expediente, documento o información administrativa, con excepción de secretos de Estado y documentos confidenciales. 
El cargo es incompatible con cualquier otro cargo público o privado, a excepción de la docencia y la investigación. Tiene prohibido participar en actividades políticas o partidistas, y en profesiones liberales.

El Defensor cuenta con facultades para decidir la estructura orgánica de la institución. En este momento, por ejemplo, cuenta con las siguientes direcciones: de Administración y Atención inmediata, Defensoría de la Mujer, de Protección Especial (dedicada a grupos especialmente vulnerables), Calidad de Vida, Gestión Administrativa, Asuntos Económicos, de Niñez y Adolescencia.

\section{GuATEMALA}

Por lo que se refiere al nombramiento del Procurador de Derechos Humanos el artículo 273 de la Constitución establece que "El Congreso de la República designará una Comisión de Derechos Humanos formada por un diputado por cada partido político representado en el correspondiente período. Esta Comisión propondrá al Congreso tres candidatos para la elección de un Procurador, que deberá reunir las calidades de los magistrados de la Corte Suprema de Justicia y gozará de las mismas inmunidades y prerrogativas de los diputados al Congreso".

En el artículo siguiente se dispone que: «El procurador de los Derechos Humanos es un comisionado del Congreso de la República para la defensa de los Derechos Humanos que la Constitución garantiza. Tendrá facultades de supervisar la administración; ejercerá su cargo por un período de cinco años, y rendirá informe anual al pleno del Congreso, con el que se relacionará a través de la Comisión de Derechos Humanos".

La institución está fuera de los poderes clásicos y ejerce su función con independencia en la protección de los derechos humanos. En este sentido, la ciudadanía muestra gran confianza hacia la institución, estando en segundo lugar tras las municipalidades (según se desprende del estudio Cultura politica de la democracia en Guatemala: 2006).

Los requisitos para poder acceder al cargo son los siguientes: guatemaltecos de origen, de reconocida honorabilidad, estar en el goce de sus derechos ciudadanos y ser abogado colegiado — con excepción de algunos jueces-. Además, el cargo es incompatible con cualquier otro empleo, con cargos directivos en sindicatos y partidos políticos, y con la calidad de ministro de cualquier religión; también es incompatible con cargos directivos de organizaciones patronales y con el ejercicio de la profesión.

Para ser elegido se necesitan como mínimo dos tercios del total de los votos del Congreso en una sesión convocada para ese efecto dentro del plazo de 30 días a contar desde la fecha de recepción de la lista de candidatos por la Junta Directiva.

Las causas de cese son: el incumplimiento manifiesto de las obligaciones que le confieren la ley y la Constitución; la participación material o intelectual 
comprobada en actividades de política partidista; la renuncia; la muerte o incapacidad sobreviviente; la ausencia inmotivada del territorio nacional por más de treinta días consecutivos; el incurrir en incompatibilidad conforme a lo previsto en la ley; la condena o sentencia firme por delito doloso.

\section{HONDURAS}

El Comisionado Nacional de los Derechos Humanos de Honduras fue creado en 1992 como un Despacho del Poder Ejecutivo. En 1995 se transformó en una institución autónoma a raíz de modificación del artículo 59 de la Constitución:

"La persona humana es el fin supremo de la sociedad y del Estado. Todos tienen la obligación de respetarla y protegerla. La dignidad del ser humano es inviolable. Para garantizar los derechos y deberes reconocidos en esta Constitución, créase la institución del Comisionado Nacional de los Derechos Humanos. La organización, prerrogativas y atribuciones del Comisionado será objeto de una ley especial».

Existe una ley orgánica y un reglamento que regulan la institución desde 1995 y 1996 respectivamente.

El Comisionado se ha enfocado no sólo en garantizar los derechos constitucionalmente reconocidos, sino también en contribuir al fortalecimiento del Estado de Derecho y en ir constituyendo un poder ciudadano hondureño conocedor de los derechos y capaz de exigirlos. De esta forma, ha aportado al proceso de modernización que ha experimentado Honduras en los últimos años ${ }^{19}$.

La figura del Comisionado es unipersonal y es la máxima autoridad en la organización, ejecución y desarrollo de las funciones y atribuciones que establece la Ley Orgánica y el Reglamento.

Para ser elegido se necesitan los siguientes requisitos: ser hondureño por nacimiento, estar en el pleno goce de sus derechos ciudadanos, ser mayor de treinta años, ser profesional de las Ciencias Jurídicas y sociales o profesional universitario versado en derechos humanos, tener una reconocida honorabilidad.

El Comisionado es elegido por el Congreso Nacional por mayoría de votos, durante un período de seis años, pudiendo ser reelegido.

Las causas de cese son: renuncia; cumplimiento del plazo para el que fue elegido; existencia de negligencia notoria en el cumplimiento de sus obligaciones; incapacidad sobrevenida o muerte.

19 PÉREZ TREMPS Y HERNÁNDEZ VALLE, La Justicia Constitucional como elemento de consolidación de la democracia en Centroamérica Ed. Tirant lo Blanch, Valencia, 2000, pág. 202. Véase igualmente : ESCOBAR ROCA,,G. Defensorías del Pueblo en Iberoamérica. Thomson Aranzadi, Pamplona, 2008, pág. 223. 
En estos supuestos, y en tanto el Congreso Nacional no proceda a la elección del Comisionado, desempeñarán sus funciones interinamente, por su orden, los Delegados Adjuntos del Comisionado Nacional de los Derechos Humanos.

\section{NICARAGUA}

El nombramiento del Procurador y Subprocurador es atribución de la Asamblea Nacional, de conformidad con el artículo 138.9 de la Constitución. Para su nombramiento será necesario el sesenta por ciento de los votos del total de los Diputados de la Asamblea Nacional, de listas separadas propuestas para cada cargo por el Presidente de la República y por los Diputados, en consulta con las asociaciones civiles pertinentes.

Los candidatos propuestos no deben tener vínculos de parentesco entre sí, ni con el Presidente de la República ni con los diputados proponentes, dentro del cuarto grado de consanguinidad y segundo de afinidad; ni deberán ser miembros de las Juntas Directivas Nacionales, Departamentales o Municipales de partidos políticos, y si lo fueren, deberán cesar en sus funciones partidarias.

La Constitución establece un plazo para presentar las listas de candidatos, que será de quince días a contar desde la convocatoria de la Asamblea Nacional para su elección. Si no hubiere listas presentadas por el Presidente de la República, bastarán las listas propuestas por los diputados.

La Asamblea Nacional, a través de Comisiones Especiales, podrá convocar a audiencias de candidatos, quienes deberán estar debidamente calificados para el cargo y su postulación deberá acompañarse de la documentación que se les solicite.

El artículo 9 de la Ley de la Procuraduría de los Derechos Humanos establece que el Procurador y Subprocurador tomarán posesión de sus cargos el día de su elección ante la Junta Directiva de la Asamblea Nacional, previa promesa de ley, y serán electos por un período de cinco años.

Los requisitos para la elección de Procurador y Subprocurador serán los siguientes: ser nacional de Nicaragua y no haber renunciado a esta nacionalidad, salvo que la hubiere recuperado cinco años antes de su elección; estar en pleno goce de sus derechos civiles y políticos, y ser de reconocida solvencia moral y profesional, no poseer antecedentes penales ni haber estado involucrado en acciones violatorias a los derechos humanos: los derechos ciudadanos se suspenden por imposición de pena corporal grave o penas accesorias específicas y por sentencia ejecutoriada de interdicción civil, tal y como establece el artículo 47 de la Constitución; haber cumplido veinticinco años de edad y no superar los setenta y cinco en el día de su elección: esta disposición parte del hecho de que con cierta edad se han alcanzado madurez, experiencia y destrezas que contribuyen al mejor desempeño del cargo; tener reconocida trayectoria y vocación en la defensa y promoción de los de- 
rechos humanos y amplios conocimientos en la materia: los candidatos deberán haberse especializado en la temática desde una perspectiva de la sociedad civil, y haberse destacado por su notoriedad y tener reconocida trayectoria en este campo. No se requiere ser Abogado ni Notario para ello, basta con su trayectoria, vocación y conocimiento en la defensa y promoción de los derechos humanos.

Las causas de cese del Procurador y Subprocurador son las siguientes:renuncia; expiración del plazo de su nombramiento; muerte o incapacidad sobrevenida; actuar con notoria negligencia en el cumplimiento de las obligaciones y deberes del cargo; haber sido condenado mediante sentencia firme

Para cesar en sus funciones en las tres primeras causas se requerirá que la vacante sea declarada por la Junta Directiva de la Asamblea Nacional; para los demás casos, se decidirá por el setenta por ciento de los diputados. Dicha votación se llevará a cabo mediante debate y previa audiencia del Procurador o Subprocurador.

\section{FUNCIONES}

En primer lugar, hay que resaltar la importancia del trabajo de los Defensores del Pueblo y los organismos internacionales de derechos humanos en todo lo que se refiere a la protección de los mismos.

Además, suponen un sistema de control de las Administraciones Públicas. Sin embargo, y a diferencia de lo que ocurre en Suecia, España ${ }^{20}$ y otros países occidentales, en Centroamérica no es ésta la principal función de la institución, sino la defensa y garantía de los derechos humanos.

Por último, sirven como parámetro de control: no sólo constatan el incumplimiento de un derecho, sino que valoran críticamente las normas ${ }^{21}$.

La labor del Defensor del Pueblo en España ${ }^{22}$ ha servido, sin duda, de inspiración para algunos de los Procuradores de Derechos del ámbito centroamericano, tal y como se va a detallar a continuación. La función primordial del Defensor del Pueblo, según el artículo 54 de la Constitución, es la defensa de los derechos fundamentales reconocidos en su titulo I. Sin embargo, aunque la norma fundamental no lo diga expresamente, esta institución funciona claramente, en cumplimiento de su fin, como un órgano de control de los tres poderes clásicos del Estado. Este control se limita, evidentemente, al terreno concreto de las eventuales violaciones de derechos y libertades fundamentales que puedan cometer los poderes ejecutivo, legislativo o judicial, lo

20 Esta institución funciona claramente, en cumplimiento de su fin como un órgano de control de los tres poderes clásicos del estado. Se trata así de un ejemplo específico de control inter órgano, según la terminología que expuso Löwenstein en su clásica Teoría de la Constitución.

21 ESCOBAR ROCA, G. El Ombudsman en el sistema internacional de derechos humanos. Contribuciones al debate. Madrid, Ed. Dykinson, 2008, pág. 26.

22 ALVAREZ CONDE. Curso de Derecho Constitucional. Ed. Tecnos, Madrid, 1992, pág. 425. 
que sin duda constituye un medio muy efectivo si se saben utilizar todos los recursos de que dispone la institución.

\section{El SALVADOR}

La competencia del Procurador para la Defensa de los Derechos Humanos es la de velar por la protección, promoción y educación en derechos humanos y por la vigencia irrestricta de los mismos (art. 194 Constitución y art. 2 del Decreto N. ${ }^{\circ} 163$ Ley para la Procuraduría para la Defensa de los Derechos Humanos (6/3/92) Además, existe el Reglamento de la Ley de la Procuraduría para la Defensa de los Derechos Humanos, de 17 de febrero de 1993.

La Procuraduría para la Defensa de los Derechos Humanos tiene su origen en los Acuerdos de Paz firmados en Méjico el 27 de abril de 1991 (ap.II, 1, c). En ellos, se establecía la creación de esta Procuraduría con la misión de promover y defender los derechos humanos en todo el país. Como consecuencia de ello, se modificaron los artículos 191 y 194 de la Constitución. Es una institución integrante del Ministerio Público.

Su competencia ${ }^{23}$ es la de velar por la protección de las víctimas de las violaciones de los derechos humanos, tanto con origen en las administraciones como en particulares. Se le reconoce la posibilidad de interponer recursos judiciales o administrativos ${ }^{24}$; elaborar informes y recomendaciones, así como emitir opiniones sobre proyectos de ley. Además, podrá "supervisar la actuación de la administración pública frente a las personas". Podemos concluir que para el cumplimiento de su mandato, la legislación salvadoreña otorga al Procurador un marco amplio de competencias ${ }^{25}$.

En relación al poder legislativo: podrá promover las reformas que contribuyan al progreso de los derechos humanos; también podrá emitir opiniones sobre proyectos de leyes que afecten el ejercicio de derechos humanos o presentar propuestas de anteproyectos de leyes para el avance de los derechos humanos en el país; así mismo, promoverá la firma, ratificación o adhesión a Tratados internacionales de derechos humanos (en este momento, por ejemplo, debiera estar promoviendo la ratificación del protocolo facultativo al Pacto de Derechos Económicos, Sociales y Culturales de 1966 (PIDESC).

En relación a la Administración Pública, tienen la facultad de supervisar la actuación de la administración pública frente a las personas. Además, debe

23 GIL ROBLES Y GIL DELGADO, A. "El Defensor del Pueblo y su impacto en España y América Latina". Revista de la Asociación Iberoamericana del Ombudsman. n. ${ }^{\circ}$ 3, 1994, pág. 70.

24 Algunos autores, como TINETTI (op. cit., pág.300) sostienen que ante la redacción tan amplia de la Constitución, hay que entender que el Procurador para la Defensa de los Derechos Humanos puede interponer, entre otros, procesos de amparo ante la Sala de lo Constitucional de la Corte Suprema de Justicia. El modelo es similar al español.

25 Vid. ESCOBAR ROCA, G. Defensorias del Pueblo en Iberoamérica. Ed. THomson Aranzadi, Pamplona, 2008, pág.151. 
crear, fomentar y desarrollar nexos de comunicación y cooperación con organismos de promoción y defensa de los derechos humanos, gubernamentales, tanto nacionales como internacionales y con los diversos sectores de la vida nacional ${ }^{26}$.

En relación a los particulares, son atribuciones del Procurador velar por el respeto y la garantía a los Derechos Humanos; investigar, de oficio o por denuncia que hubiere recibido, casos de violaciones a los Derechos Humanos; asistir a las presuntas víctimas de violaciones a los Derechos Humanos; promover recursos judiciales o administrativos para la protección de los Derechos Humanos $^{27}$; vigilar la situación de las personas privadas de su libertad. Será notificado de todo arresto y cuidará que sean respetados los límites legales de la detención administrativa; practicar inspecciones, donde lo estime necesario, en orden a asegurar el respeto a los Derechos Humanos;; promover reformas ante los órganos del estado para el progreso de los Derechos Humanos; promover y proponer las medidas que estime necesarias en orden a prevenir violaciones a los Derechos Humanos; formular conclusiones y recomendaciones públicas o privadamente; elaborar y publicar informes; desarrollar un programa permanente de actividades de promoción sobre el conocimiento y respeto de los Derechos Humanos; velar por el estricto cumplimiento de los procedimientos y plazos legales en los distintos recursos que hubiere promovido o en las acciones judiciales en que se interesare; velar por el respeto a las garantías del debido proceso y evitar la incomunicación de los detenidos; llevar un registro centralizado de personas privadas de su libertad y de centros autorizados de detención; presentar propuestas de anteproyectos de leyes para el avance de los derechos humanos en el país; promover la firma, ratificación o adhesión a tratados internacionales sobre derechos humanos; emitir resoluciones de censura pública contra los responsables materiales o intelectuales de violaciones a los derechos humanos; procurar la conciliación entre las personas cuyos derechos han sido vulnerados y las autoridades o funcionarios señalados como presuntos responsables, cuando la naturaleza del caso lo permita.

\section{Costa Rica}

No existe previsión constitucional en este país. La competencia del Ombudsman de proteger los derechos e intereses de los habitantes, velando

26 http://www.unfpa.org/derechos/paises.htm (consulta: 13 julio 2010).

27 Vid. art. 194 de la Constitución y art.11 de la Ley de la Procuraduría para la Defensa de los Derechos Humanos. Tal y como recuerdan MONTECINO Y NÚÑEZ RIVERO: “Y ello, partiendo de la interpretación de que con la iniciación de un proceso de inconstitucionalidad pueda atacar normas jurídicas que al ser aplicadas puedan afectar a los derechos fundamentales". "Protección jurisdiccional de los derechos en el ordenamiento jurídico salvadoreño". Teoría y realidad constitucional, pags. 207-240. La misma idea se recuerda por parte de los citados autores en El Estado y la Constitución Salvadoreña, Unión Europea-Corte Suprema de Justicia, San Salvador. 2000., pág.341. 
por que el funcionamiento del sector público se ajuste a los principios y normas de derechos humanos está prevista por ley (art. 1 Ley de la Defensoría de los Habitantes N.o 7319 (5/11/92). Reformada por Ley 7423 del 18/07/94, Ley 7741 del 19/12/97, Ley 7935 del 25/10/99).En primer lugar, vela por el buen funcionamiento del sector público (que incluye toda persona, órgano, ente o institución de derecho público, o que participe, de algún modo, en la explotación de concesiones, la prestación de servicios públicos, o en el ejercicio de alguna función pública. También se incluyen las personas jurídicas participadas mayoritariamente por fondos públicos). La Defensoría puede iniciar cualquier investigación, de oficio o a instancia de parte, tendiente a esclarecer actuaciones materiales, actos u omisiones de la actividad administrativa del sector público.

En cuanto al sistema penitenciario, la labor de la Defensoría de los Habitantes de protección de los derechos de los reclusos ha sido destacada por el V Informe sobre Derechos Humanos de la Federación Iberoamericana del Ombudsman, relativo al sistema penitenciario, en especial respecto de la supervisión a las infraestructuras de los centros, la salud de los internos y la situación de mujeres y niños ${ }^{28}$.

Por lo que se refiere al poder legislativo, al tratarse la Defensoría de un órgano adscrito al Poder legislativo, cuenta con amplias facultades que inciden en el quehacer legislativo, y que se traduce en una autonomía de facto, pues está facultada para presentar proyectos de ley y de reformas de ley, además de emitir criterios sobre los proyectos de ley por posibles vulneraciones de derechos. Goza de legitimación activa para interponer recursos de inconstitucionalidad contra leyes, y puede conocer de actos u omisiones administrativas de la Asamblea Legislativa que vulneren los derechos e intereses de los habitantes.

En cuanto al poder judicial, la Defensoría no puede conocer cuestiones relativas a las potestades constitucionales y legales de los órganos jurisdiccionales del poder judicial. Esta limitación implica que la defensoría no puede realizar control ni sobre resoluciones jurisdiccionales ni sobre asuntos sobre los cuales esté pendiente una resolución judicial (art. 19.2 de la Ley).

Por otro lado, no puede intervenir respecto de resoluciones del Tribunal Supremo de Elecciones en materia electoral (art. 12.11 Ley).Además, en cuanto a las irregularidades administrativas del poder Judicial, se las comunica a la Corte Suprema de Justicia o Inspección Judicial (art. 12.4 Ley).

Se admiten, en todo caso, dos supuestos de intervención de la defensoría sobre asuntos que son investigados por el Poder Judicial: a) Investigación sobre aspectos generales del asunto en trámite en la vía judicial; b) Investigación sobre aspectos no jurisdiccionales del proceso;

28 FIO, 2007. Respecto a Costa Rica, pág. 437. 


\section{Guatemala}

El Procurador deberá defender los DDHH establecidos en la Constitución y tratados internacionales ratificados (art. 8 Ley). El Procurador no podrá entrar al examen de aquellas quejas sobre las que esté pendiente resolución judicial (art. 32 Ley de la Comisión de los Derechos Humanos del Congreso de la República y de la Procuraduría de Derechos Humanos. (Decreto 54-86, Ley) Reformado por Decreto 32-87 Código Procesal Penal (art. 467 a 469).

La Comisión de Derechos Humanos del Congreso de la República, es designada por el Congreso de la República y esta integrada por un diputado de cada partido político representando en el correspondiente periodo. Esta comisión tiene atribución constitucional de proponer al pleno del Congreso la terna de la cual deberá escogerse al magistrado de conciencia.

El Procurador de los Derechos Humanos es electo por el pleno del Congreso de la República por un periodo improrrogable de cinco años. La Ley de la Comisión de Derechos Humanos del Congreso de la República y el Procurador de los Derechos Humanos le fija otras atribuciones relacionadas con programas de promoción y enseñanza de derechos humanos, con especial énfasis en investigaciones, campañas de divulgación y publicaciones; relación con instituciones orientadas a la misma actividad; participación en eventos internacionales; divulgación del informe anual, elaboración del presupuesto y funciones administrativas internas. También el Procurador de los Derechos Humanos cuenta con el apoyo de los medios de comunicación, organizaciones no gubernamentales de derechos humanos, asociaciones en asuntos de su interés y toda la ciudadanía. Asimismo, el señalamiento de hechos contrarios al marco protector de los derechos humanos, las denuncias de violación a esos derechos fundamentales, que corresponden a esas instituciones y personas, relaciona íntimamente con la función de proceso, investigación y resolución de las mismas que corresponde al Procurador. En contraparte, el respeto a las decisiones del Magistrado de Conciencia por parte de las autoridades, es indispensable para que la Procuraduría se fortalezca y sea eficaz.

La Comisión Presidencial Coordinadora de la Política del Ejecutivo en Materia de Derechos Humanos es una entidad del gobierno, dependiente directamente de la Presidencia de la República creada para lograr la mejor coordinación de la acción de los Ministerios e Instituciones del Organismo Ejecutivo para hacer ejecutiva la vigencia y protección de los derechos humanos; así como garantizar la comunicación y cooperación de el Ejecutivo con el Organismo Judicial y la Procuraduría de los Derechos Humanos, en lo que corresponde a tales derechos. Está integrada por un representante personal del Presidente de la República, quien la preside, los Ministerios de Relaciones Exteriores, Defensa Nacional, Gobernación, el jefe del Ministerio Público y el coordinador de la comisión de la paz. 


\section{HONDURAS}

El Comisionado Nacional de Derechos Humanos tiene la misión de garantizar los derechos y libertades reconocidos en la Constitución y tratados ratificados (art. 59 Constitución y art. 1 y 9 Decreto N. ${ }^{\circ} 191-94$ (15/12/94), ratificado por decreto 2-95 (7/2/95): Ley Orgánica del Comisionado Nacional de los Derechos Humanos de Honduras (21/11/95). No entrará al examen individual de quejas sobre las que esté pendiente resolución judicial, (art. 26 Ley). No podrá modificar sentencias, pero velará por celeridad y libre acceso ante los órganos jurisdiccionales, (art. 42 Ley). No podrá modificar o anular actos de la Administración o sentencias judiciales (art. 42 Ley).

El Comisionado Nacional de los Derechos Humanos de Honduras es un Ombudsman, un defensor del pueblo que actúa como una alternativa gratuita y directa de mediación entre el Estado y el Ciudadano. Promueve la seguridad y la integridad de todos los habitantes del país, actuando con valentía, integridad, solidaridad, objetividad, respeto y en alianza con los mejores hombres y mujeres del mundo. Se trata de una institución independiente, reconocida por su eficiencia y compromiso con la defensa y promoción de la dignidad de todas las personas.

Al interior del Ministerio Público, la Fiscalía Especial de Derechos Humanos es una unidad del Ministerio Público encargada de investigar las violaciones a los derechos humanos cometidas por autoridades civiles o militares que se encuentran tipificadas como delitos en el Código Penal. Ejerce, además, la acción penal pública entre los tribunales competentes en representación de la sociedad. Vela, en coordinación con otros organismos públicos o privados, por el respeto de los derechos humanos. Vela por la pronta, expedita y correcta administración de justicia y porque en los juzgados y tribunales de la república se respeten las garantías judiciales y el debido proceso. Vigila que en las Cárceles, Penitenciarías, Granjas Penales, Centros de Corrección y cualquier otro establecimiento o centro de Detención, Reclusión o Prisión, sean respetados los Derechos Humanos y Constitucionales de los detenidos, presos y reclusos; así como investiga las condiciones en que estos se encuentran y tomar las medidas legales apropiadas para mantener o restablecer los derechos humanos cuando se compruebe que han sido o son menoscabados o quebrantados. Defiende y promueve la independencia y autonomía de los jueces y Magistrados en el ejercicio legítimo de sus funciones. Investiga si alguna persona se encuentra detenida o presa ilegalmente o cohibida de cualquier modo en el goce de su libertad individual o sufra vejámenes, torturas, exacciones ilegales o coacción; denunciar estos hechos ante quien corresponda, para los efectos de exhibición personal; y a su vez ejercita las acciones penales a que hubiere lugar. 


\section{NiCARAGUA}

La misión del Ombudsman en el país es la de promover, defender y tutelar garantías constitucionales y derechos humanos, a cuyo efecto podrá vigilar y controlar la actividad de la administración pública (art. 3 y 4 Ley de la Procuraduría para la defensa de los derechos humanos. Ley no. 212, aprobada el 13 de diciembre de 1995).

No se atenderán denuncias sobre hechos que estén pendientes de resolución judicial, salvo que se fundamenten en retardación de justicia (art. 28 Ley). Ley).

En los Estados de Excepción no se suspenden sus atribuciones (art. 22

La Procuraduría de Derechos Humanos (PDDH), es la dependencia autónoma de derechos humanos financiada por el gobierno, se mantuvo vacante hasta diciembre de 2004, cuando se seleccionó a Omar Cabezas como el nuevo Procurador de Derechos Humanos. También hay procuradores para asuntos de la niñez, de la mujer, y de los indígenas. La Procuraduría de los Derechos Humanos (PDDH) investiga violaciones a los derechos humanos con independencia de la administración, persiguiendo casos aun cuando entran en contradicción con las políticas de gobierno. Muchos de los casos que recibe incluyen asuntos económicos y sociales, como el acceso a la salud, la educación y la seguridad social, junto como temas relacionados con los derechos humanos.

El Consejo Nacional para la Atención y Protección de la Niñez (CONAPINA) es una institución casi gubernamental compuesta por instituciones del gobierno, organismos no gubernamentales e internacionales de alto nivel, y encargada de formular la política nacional sobre la niñez.

\section{PRINCIPALES RETOS DE LA INSTITUCIÓN.}

\section{AVANZAR EN EL REFORZAMIENTO DE LAS INCIPIENTES DEMOCRACIAS}

Entre las líneas estratégicas del Procurador guatemalteco para 2007-2011 aparece la de contribuir a la gobernabilidad democrática ${ }^{29}$. Sería deseable que estas instituciones continuasen siendo un factor activo de intermediación entre el Estado y la sociedad, para el mantenimiento de la gobernabilidad democrática del país. Las herramientas utilizadas en Guatemala, como las mesas de diálogo, mapas de riesgo y pactos locales de gobernabilidad deben seguir utilizándose.

Maiorano $^{30}$ resalta esta idea de que si el Ombudsman en la región centroamericana ha estado especialmente vinculado a la defensa de los derechos

29 Diez Líneas Estratégicas del Procurador para la Defensa de los Derechos Humanos en el período 2007/2011, 2007.

30 Op, cit., pág. 269. 
humanos ha sido por la inestabilidad política que ha caracterizado su vida institucional, la falta de control efectivo sobre los poderes públicos, y su carácter de países en vías de desarrollo. Sin duda el papel de los defensores ha ayudado, indirectamente, a reforzar los sistemas democráticos ${ }^{31}$.

Son muchos los retos que debe enfrentar esta institución en lo que se refiere a consolidar los sistemas democráticos: encarnar la esperanza colectiva de mayor justicia social; afrontar sus conflictos de interés con los poderes tradicionales -económicos, políticos, militares—; luchar para superar los bajos índices de desarrollo humano, la inseguridad, la falta de equidad de género, entre otros.

CONSOLIDAR SU PAPEL COMO DEFENSOR DE LOS DERECHOS HUMANOS, PROMOVIENDO LA CULTURA DEMOCRÁTICA Y DE RESPETO A LOS DERECHOS

Los procuradores deben potenciar su capacidad de supervisión y acompañamiento a las instituciones públicas y privadas, sobre todo a aquellas que por su naturaleza deben estar en primera línea en esta tarea de promoción.

El papel de los procuradores centroamericanos de derechos humanos está fuera de toda duda ${ }^{32}$. En todos los países van adquiriendo progresivamente mayor relevancia. Incluso en los países de mayores convulsiones internas, los Ombudsman han sido un instrumento mediador de participación y comunicación entre los sectores más maltratados de la población y los gobiernos.

De hecho, en su origen, los procuradores surgieron con mucha fuerza por la necesidad de mejorar las instituciones y procedimientos tradicionales de defensa de los derechos humanos.

Además de su tarea de recibir reclamaciones y denuncias relacionadas con los derechos humanos, tienen una labor de educación y denuncia, que se refleja en sus informes de actuación.

Algunas conclusiones que pueden extraerse de los datos que arrojan los informes de los Ombudsman son las siguientes:

En cuanto al número de denuncias admitidas:

En Honduras, en el primer semestre del año 2007, la Procuraduría para la Defensa de los Derechos Humanos, a través del Departamento de Defensoría, adscrita a la Dirección Nacional de Defensa y Promoción, recibió un total de 1,030 denuncias, lo que denota un aumento significativo del 35\% en relación con las denuncias recibidas durante el mismo periodo del año 2006. (765 denuncias). En Nicaragua se recibieron alrededor de 2000 denuncias.

31 VALLADARES LANZA, L.: "The challenges facing the Ombudsman in Latin America". The International Ombudsman Year. Kluwer Law International. USA; 2008, vol.2, pág. 160.

32 DÍAZ RODRÍGUEZ, F."Caracterización de los procuradores centroamericanos de derechos humanos». IRELA, Guatemala,1994. 
En cuanto a los derechos más vulnerados:

En el caso hondureño, siguiendo la labor defensorial y promocional de los derechos humanos con enfoque de genero, generacional y multicultural, esta Procuraduría en el presente año ha mantenido la tendencia de la denuncia identificada por grupos vulnerables, tales como casos de mujer, niñez y adolescencia, adulto mayor, privados y privadas de libertad, migrantes, consumidores, VIH, pueblos indígenas entre otros.

En Nicaragua los derechos más denunciados fueron el de libertad, integridad, debido proceso, derecho de petición, propiedad, salud, derechos laborales.

En Guatemala, los derechos que más denuncias ocasionaron ante el Procurador de Derechos humanos fueron el de libertad, seguridad y debido proceso, con un aumento importante de los derechos económicos, sociales y culturales.

En Costa Rica, los derechos más vulnerados han sido: el de eficiencia en la prestación del servicio público, salud, medio ambiente, trabajo, empleo, integridad personal.

En El Salvador, los derechos que más denuncias recibieron fueron derechos civiles y políticos, como el derecho al debido proceso, libertad, integridad, etc. En cuanto a los derechos económicos, sociales y culturales, el informe de la Procuradora para la Defensa de los Derechos Humanos de 2006 señala las violaciones referentes a estos, con especial detenimiento en los derechos a la educación, salud y trabajo.

Por lo que se refiere a las instituciones más denunciadas:

En Honduras, entre las instituciones mayormente denunciadas como presuntas violadoras de derechos humanos, igual que en el año 2006, la Policía Nacional ocupa el primer lugar, seguido del Poder Judicial, otros ministerios e instituciones del Estado (MINSA, MINED, INSS, MITRAB, Ministerio de la Familia, Sistema Penitenciario Nacional, etc).

En Nicaragua el mayor número de denuncias tuvo como objeto a los particulares, seguidos de la Policía, Poder Judicial, y otras instituciones del Estado.

En Costa Rica, las instituciones más denunciadas ${ }^{33}$ fueron las siguientes: Caja Costarricense de Seguro Social 13,7\% del total de las denuncias; Instituto Mixto de Ayuda Social 12,9\%; Municipalidades 10,7\%; Ministerio de Educación Pública 8,7\%; Hospitales 6,3\%; Instituto Costarricense de Acueductos y Alcantarillados 4,8\%; Instituto Costarricense de Electricidad 4,1\%; Ministerio de Salud 3,5\%; Ministerio de Obras Públicas y Transporte 3,4\%; Bancos 2,7\%; Instituto Nacional de Seguros 2,6\%;Dirección General de Adaptación Social 2,5\%;Corte Suprema de Justicia 2,2\%;Comisión Nacional del Consumidor 2,0\%; Ministerio de Seguridad Pública 1,9\%.

33 Vid. Informe Anual de Labores de 2009 de la Defensoría de los Habitantes, pág. 350. 


\section{DESARROLLO INSTITUCIONAL Y AMPLIACIÓN DE COBERTURA}

Uno de los retos de la institución en Centroamérica es un mayor desarrollo institucional, ampliando la cobertura de actuación y multiplicando la presencia del Defensor del Pueblo en más lugares de los países. Además, es importante que se apueste por el fortalecimiento de las capacidades profesionales, organizativas, logísticas, administrativas y financieras para elevar la calidad de los servicios que se prestan a la población.

En este sentido, es muy importante analizar el presupuesto de la institución y su procedencia: en la medida en que el poder político controle el mismo, y se renueve anualmente, existe una posibilidad grande de que se convierta en una forma de control y limitación de la actuación de la institución ${ }^{34}$.

Sin duda el papel de la financiación internacional es de vital trascendencia: ésta puede consistir en ayuda financiera, pero también en presión diplomática a favor de su actuación. En El Salvador este aporte supone el 10\% del presupuesto del Procurador, mientras en Guatemala es del $15 \%$ y en Honduras del 40.

Es interesante comparar la situación presupuestaria de las diferentes instituciones en la región: el Ombudsman en Costa Rica cuenta con un presupuesto que crece anualmente de forma constante, lo que supone una apuesta por la institución; el de El Salvador, sin embargo, equivale al 0,1\% del Sector Público no financiero y es el presupuesto más bajo de todo el Ministerio Público; Honduras y Guatemala cuentan con un presupuesto muy reducido, que apenas permite sufragar gastos de personal y arrendamiento de locales; ello hace que existan pocas delegaciones de la Oficina Central en las provincias, lo que dificulta el acceso de los ciudadanos no capitalinos a la institución.

Papel impulsor de la SALVAGUARDA DE los DEREChOS ECONÓMICOS, SOCIALES Y CULTURALES

Existen muchos autores que defienden este papel del Ombudsman en Centroamérica: Maiorano ${ }^{35}$ y Gross Espiell ${ }^{36}$, entre otros.

Concepto y fundamentación de los derechos económicos, sociales y culturales ${ }^{37}$.

34 Vid. FREDIK UGGLA, op. cit., pág. 435. Este autor expone estas dificultades y subraya el caso nicaragüense, donde la institución sufrió en 2000 un recorte presupuestario del $40 \%$.

35 Op. cit., pág. 270.

36 "El Ombudsman. Su interés en la actual situación de Hispanoamérica". Revista de las Cortes Generales, Madrid, n. ${ }^{\circ}$ 4, 1985, pág. 204.

37 Vid. el número monográfico sobre el tema: ZAPATERO, V; GARRIDO GÓMEZ, I. (edit.). "Los derechos sociales como una exigencia de la justicia". Cuadernos de Derechos Humanos. Universidad de Alcalá-Defensor del Pueblo-Cátedra Democracia y Derechos Humanos. Madrid, 2009. 
Comenzaremos con unas aclaraciones en torno al concepto de derechos sociales.

Uno de los obstáculos que frecuentemente se aducen para evitar que ni los jueces ni las instituciones de derechos humanos — como los Ombudsman- velen por el respeto y protección de los derechos económicos y sociales es el hecho de su falta de justiciabilidad. En este sentido, existe una potente corriente doctrinal que defiende que estos derechos sí pueden llevarse ante la justicia e instituciones de derechos humanos ${ }^{38}$.

38 Vid. entre otros, ABRAMOVICH, V. - COURTIS, CH.. Los derechos sociales como derechos exigibles. Trotta, Madrid, 2002; ABRAMOVICH, V. - "Una aproximación al enfoque de derechos en las estrategias y políticas de desarrollo". Revista de la CEPAL 88, abril 2006; vid. asimismo Perfecto Andrés Ibáñez, en "Garantía judicial de los derechos humanos", Claves, núm. 90, marzo 1999, pág.10-17, citado por GINER DE GRADO, C. "Derechos humanos, derechos sociales y normas constitucionales" en Documentación Social, n. ${ }^{\circ}$ 114, 1999, pág.49.

ABRAMOVICH - COURTIS exponen esta cuestión extensamente en "Apuntes sobre exigilidad judicial de los derechos sociales. Disponible on line: http://www.juragentium.unifi.it/es/ surveys/latina/courtis.htm (consulta: 1 de junio 2010).

«En la práctica, existen obstáculos para hacer plenamente exigibles los derechos sociales establecidos en una Constitución por vía judicial ante, claro está, el incumplimiento de los poderes obligados primariamente, es decir, los poderes políticos. Algunos de estos obstáculos son los siguientes:

a) La determinación de la conducta debida. Un primer obstáculo está vinculado con la falta de especificación concreta del contenido de estos derechos. Cuando una Constitución o un tratado internacional de derechos humanos hablan de derecho a la salud, derecho a la educación, derecho al trabajo o derecho a la vivienda, resulta difícil saber cuál es la medida exacta de las prestaciones o abstenciones debidas. Evidentemente la exigencia de un derecho en sede judicial supone la determinación de un incumplimiento, cosa imposible en el caso de los derechos sociales.

A este comentario hay que replicar lo siguiente: la determinación del contenido de todo derecho de raigambre constitucional se ve afectado por el mismo inconveniente, derivado de la falta de concreción con que se redactan las normas jurídicas. ¿Qué significa "propiedad"? ¿Cuál es el tipo de "expresión" protegida por la prohibición de censura previa? ¿Cuál es el alcance de la noción de «igualdad»? Sin embargo, esta dificultad jamás ha llevado a la afirmación de que los derechos civiles no sean derechos, o no sean exigibles judicialmente, sino más bien a la tarea de especificación de su contenido y límites, a partir de distintos procedimientos de afinamiento de su significado — principalmente, la reglamentación legislativa y administrativa, la jurisprudencia y el desarrollo de la dogmática jurídica. En el plano internacional, las Observaciones Generales del Comité de Derechos Económicos, Sociales y Culturales constituyen otro ejemplo de esta tarea de especificación del contenido de los derechos establecidos en el Pacto Internacional respectivo. Lo mismo puede predicarse del desarrollo de prácticas de exigibilidad de derechos sociales por la vía judicial ante los tribunales nacionales. El desarrollo de una dogmática de los derechos sociales, tanto en sede nacional como internacional, constituye una tarea en muchos casos pendiente, que ofrecerá elementos de especificación más detallada del contenido de los derechos sociales.

Por otro lado, los problemas de falta de especificación del contenido de un derecho son típicos de las normas constitucionales o de tratados de derechos humanos, dado que se trata de las normas de mayor nivel de generalidad del orden jurídico. Ello permite mayor flexibilidad y adaptabilidad a instrumentos normativos cuya modificación es normalmente más gravosa que la de la legislación ordinaria, ofrece a los órganos encargados de especificar el contenido de los derechos contenidos en esos instrumentos un margen de elección compatible con la prudencia y necesidad de evaluación de la oportunidad que requiere la toma de cualquier decisión política, preserva la brevedad y concisión que hacen de estos documentos el catálogo de principios fundamentales 
Si se acepta que la finalidad del Estado es garantizar la igual libertad de las personas, debe admitirse que el ejercicio efectivo de la libertad puede violarse no sólo por acción, como pretenden Nozick ${ }^{39}$ y otros autores conserva-

del Estado de derecho. A estos argumentos hay que añadir el hecho de la determinabilidad fáctica: en muchos supuestos, pese a que la conducta debida no resulta específicamente reglada por un texto normativo, fácticamente sólo existe uno o un número limitado de cursos de acción determinables para el respeto, garantía o satisfacción del derecho de que se trate. Por ejemplo, en el contexto del derecho a la asistencia sanitaria, en materias vinculadas con el desarrollo de tratamientos médicos, producción de medicamentos o vacunas ante cuadros concretos de enfermedad, la discrecionalidad del Estado para optar entre cursos de acción alternativos resulta claramente limitada. b) La autorrestricción del Poder Judicial frente a cuestiones políticas y técnicas: Otro de los tradicionales obstáculos para hacer justiciables los derechos sociales reside en el criterio sumamente restrictivo que suelen emplear los jueces para evaluar su facultad de invalidar decisiones que pueden calificarse como políticas. Así, cuando la reparación de una violación de derechos sociales importa una acción positiva del Estado que pone en juego recursos presupuestarios, afecta de alguna manera el diseño o la ejecución de políticas públicas, o implica tomar una decisión acerca de qué grupos o sectores sociales serán prioritariamente auxiliados o tutelados por el Estado, los jueces suelen considerar que tales cuestiones son propias de la competencia de los órganos políticos. c) La inadecuación de los mecanismos procesales tradicionales para la tutela de derechos sociales. Otro obstáculo importante para la exigibilidad de los derechos sociales es la inadecuación de los mecanismos procesales tradicionales para su tutela. Las acciones judiciales tradicionales tipificadas por el ordenamiento jurídico han sido pensadas para la protección de los derechos civiles clásicos. La cuestión remite a una de las discusiones medulares en materia de definición de los derechos, consistente en la relación entre un derecho y la acción judicial existente para exigirlo. Algunas dificultades conceptuales que plantea esta discusión tiene directa relación con la estrecha vinculación de la noción tradicional de derecho subjetivo, la noción individual de propiedad y el modelo de Estado liberal. Dado que gran parte de las nociones sustanciales y procesales propias de la formación jurídica continental surgen del marco conceptual determinado por esta vinculación, muchas de las respuestas casi automáticas que se articulan frente a la posible justiciabilidad de los derechos económicos, sociales y culturales insisten en señalar la falta de acciones o garantías procesales concretas que tutelen los derechos sociales. Para verificar las dificultades que genera el marco teórico en el que se fundan las acciones tradicionales para proteger adecuadamente derechos sociales basta señalar algunos ejemplos, como que las sentencias que condenan al Estado a cumplir obligaciones de hacer no cuentan con resguardos procesales suficientes y resultan por ello de dificultosa ejecución. Sin embargo, la inexistencia de instrumentos procesales concretos para remediar la violación de ciertas obligaciones que tienen como fuente derechos económicos, sociales y culturales no se sigue de ningún modo la imposibilidad técnica de crearlos y desarrollarlos. d) La escasa tradición de control judicial en la materia: Existe otro obstáculo de índole cultural, que es la ausencia de tradición de exigencia de estos derechos — en especial en los casos de derechos que se definen fundamentalmente por una prestación, como los derechos a la salud, educación, vivienda, entre otros- a través de mecanismos judiciales. Pese a la existencia de normas de jerarquía constitucional que consagran estos derechos, concepciones conservadoras acerca del papel institucional del Poder Judicial y de la separación de poderes, han provocado una escasa práctica de exigencia judicial de estos derechos, y un menosprecio de las normas que los instituyen". Hay que destacar, sin embargo, algunos casos recientes de exigibilidad ante los tribunales del derecho al agua, tal y como se ha señalado en el libro Derecho al Agua publicado en 2008 por Ingeniería sin Fronteras y Prosalus en España, pág. 107.

39 Vid. NOZICK, R.:, "Anarchy", State and Utopia, Oxford, 1974. Citado por: PISARELLO, G. "Los derechos sociales en el constitucionalismo democrático". Cuadernos electrónicos de filosofía del derecho, n. ${ }^{\circ}$ 4, 2001 (Ejemplar dedicado a “El contenido mínimo de los derechos sociales de los inmigrantes. Propuestas e indicadores de evaluación). 
dores, sino también por omisión. En ese sentido, al vínculo entre la libertad negativa y la libertad positiva corresponde el vínculo entre los derechos de libertad y los derechos sociales. Los primeros suponen principalmente deberes generales negativos, de abstención, y los segundos, deberes generales positivos, de prestación. Ambos tienen una misma justificación: proteger los bienes primarios, o las necesidades básicas, de los seres humanos.

Ahora bien, para garantizar la concesión de estos derechos sociales en la práctica, el constitucionalismo propone una serie de controles sobre aquellos poderes encargados de prestarlos: el Estado y el mercado.

Los poderes públicos son los principales encargados de proveer una serie de bienes y servicios que los ciudadanos no podrían obtener del mercado. Con esa finalidad, deben llevar adelante una permanente tarea de redistribución y transferencia de recursos, fundamentalmente por vía impositiva, que les permita financiar esas prestaciones.

Esto suele acabar frustrándose. La aguda crisis de representatividad que afecta a los parlamentos actuales y a la administración en general, exige que la pretensión de certeza y previsibilidad que entraña el constitucionalismo, se traduzca en mecanismos jurídicos que eviten que los derechos sociales básicos se garanticen para todos.

Los poderes privados, de mercado, dominan por su parte el ámbito en el que se genera gran parte de los recursos susceptibles de satisfacer las necesidades básicas de las personas. Para el constitucionalismo liberal clásico, este espacio económico resultaba intocable. Su protección exigía, de los poderes públicos, una actitud lo suficientemente firme como para mantener alejadas posibles intromisiones de terceros, a la propiedad y a la seguridad del tráfico. Por eso, los derechos fundamentales se configuraban verticalmente, frente al Estado, al tiempo que se cubría el derecho de propiedad con garantías reforzadas.

El constitucionalismo contemporáneo ha cambiado esta visión. Nace, por ejemplo, la problemática de la Drittwirkung, en virtud de la cual los derechos adquieren un sentido igualitario, y proyectan su sombra no sólo sobre los poderes públicos, sino también sobre los privados ${ }^{40}$. En otras palabras, los derechos fundamentales ya no sólo se configuran verticalmente, frente al Estado, sino que extienden su fuerza obligatoria también horizontalmente, frente a terceros. Esto no significa, sin embargo, que todas las prestaciones sociales, constitucionalmente previstas, puedan exigirse directamente de los particulares.

En Latinoamérica, donde los derechos sociales no han gozado de reconocimiento legal y de garantías suficientes, la falta de regulación jurídica y la lógica económica del interés privado han hecho que poderes profundamente arbitrarios hayan sustituido a la lógica política de los intereses generales.

Los derechos económicos, sociales y culturales en las constituciones de los países centroamericanos.

40 Vid. VEGA, P. DE, "La crisis de los derechos fundamentales en el Estado social", Derecho y economía en el Estado social, Madrid, Tecnos, 1988, pp. 130-135. 
Las constituciones de los países, cuando se refieren al mandato de los defensores, hacen alusión a su competencia en relación a los derechos humanos o derechos fundamentales, por lo que no hay impedimento legal para incluir los derechos económicos, sociales y culturales. La tendencia casi unánime en la región ha sido la de reconocer los derechos económicos, sociales y culturales en la lista de derechos fundamentales reconocidos por las distintas constituciones. De modo que por esta vía, la especificación constitucional de qué debe entenderse por derechos humanos o derechos fundamentales incluye a los derechos económicos, sociales y culturales, y esto vale para dar contenido al mandato de las instituciones nacionales de derechos humanos.

El derecho internacional de los derechos humanos también apunta en esta dirección. Un Estado asigna significado a esta expresión cuando ratifica o accede a tratados internacionales de derechos humanos. Este argumento tiene aún más peso si el ordenamiento jurídico ha adoptado una posición monista en torno a las relaciones entre derecho internacional y derecho interno - es decir, cuando la adopción de un tratado internacional tiene el efecto de incorporar el tratado al derecho interno. Y esta es justamente la regla en todos los países de la región -independientemente de alguna divergencia en las soluciones relativas a la jerarquía normativa de los tratados internacionales en el derecho interno. Pues bien, la tendencia generalizada de los países de la región es la ratificación tanto de tratados de derechos humanos que reconocen derechos civiles y políticos, como de aquellos que reconocen derechos económicos, sociales y culturales. También es frecuente que la descripción del mandato de las instituciones nacionales incluya la protección y promoción de los derechos humanos reconocidos en tratados internacionales ${ }^{41}$. De modo que puede concluirse que cuando las constituciones o las leyes reglamentarias definen el mandato de las instituciones nacionales haciendo referencia al término "derechos humanos", esta referencia incluye a los derechos económicos, sociales y culturales.

Con todo, es posible que existan algunos problemas de exclusión de algunos temas o materias específicas del mandato de las instituciones nacionales. En algunos casos puntuales, se excluyen los derechos laborales. En otros casos - más comunes-, el mandato de las instituciones nacionales de derechos humanos se limita al control de las acciones u omisiones cometidas por el Estado o por agentes públicos, y excluye las cometidas por particulares ${ }^{42}$.

41 Ver, por ejemplo, en Costa Rica, Ley 7319 del 17 de noviembre de 1992, artículo 1; Constitución Política de la República de Guatemala, artículo 274; Constitución de la República de Honduras, artículo 59; Constitución Política de los Estados Unidos Mexicanos, artículo 102.B; Nicaragua, Ley de la Procuraduría para la Defensa de los Derechos Humanos, artículo 5; Constitución de Panamá, artículo 129;

42 Existen países que excluyen esta posibilidad, como España, en el artículo 1 de la LODP Ver, así mismo, Constitución Política de la República de Guatemala, artículos 274 y 275; Constitución Política de los Estados Unidos Mexicanos, artículo 102.B; Nicaragua, Ley de la Procuraduría para la Defensa de los Derechos Humanos, artículo 37. En contraste, existen en Centroamérica casos de reconocimiento explícito de la inclusión, dentro del mandato de las instituciones nacio- 
Estas exclusiones pueden dejar de lado importantes violaciones de derechos sociales, en aquel universo de casos en los que estas violaciones correspondan a relaciones entre particulares. Estos casos no son extraños: derechos tales como los derechos laborales, el derecho a la salud, el derecho a la educación, el derecho a la vivienda o el derecho a la alimentación involucran frecuentemente vínculos entre particulares. Esta tendencia se ha agudizado con el proceso de privatización de servicios públicos acaecida en muchos países de la región durante los años noventa, que puso en manos de prestadores privados o transfirió al sector privado de manera total o parcial la prestación de servicios públicos destinados a la satisfacción de derechos sociales como la provisión de servicios de agua, de salud, de educación o la administración de la seguridad social. De modo que la exclusión de actos u omisiones de sujetos privados del mandato de las instituciones nacionales de derechos humanos puede tener el efecto de ignorar un universo importante de potenciales violaciones a derechos económicos, sociales y culturales.

Tales exclusiones, sin embargo, pueden ser parcialmente modificadas a través de algunas estrategias interpretativas —en la medida, claro está, en que éstas tengan soporte normativo suficiente. Comentaremos dos de ellas.

La primera es la aceptación de la aplicación de la prohibición de discriminación también a las relaciones entre particulares. De modo que, en principio, cabría la posibilidad de trabajar temas en los que la afectación de derechos económicos, sociales y culturales provenga de particulares, en aquellos casos en los que la situación pueda calificarse como violatoria de la prohibición de discriminación. Esta interpretación haría posible la competencia de las instituciones nacionales, por ejemplo, en casos de violación del derecho a la salud o a la educación por parte de prestadores de servicios de salud o establecimientos educativos privados, siempre que la situación denunciada incluya dimensiones de discriminación.

Una segunda estrategia para disminuir el posible efecto pernicioso de la exclusión de las relaciones entre particulares del mandato de las instituciones nacionales de derechos humanos es la "traducción" de una violación cometida entre sujetos privados en una violación imputable al Estado por falta de regulación, vigilancia o supervisión adecuada. Aunque es claro que esta forma de encuadrar la situación tiene desventajas, dado que el responsable directo de la violación es el sujeto privado y no el Estado, de todos modos puede ofrecer una salida práctica en los casos en los que no haya otra manera de salvar la exclusión. Algunos autores ${ }^{43}$ apuestan por esta solución en casos como los de violencia familiar, en que la causa de la misma puede entenderse que es la omisión del Estado, que no regula suficientemente la materia. El

nales de derechos sociales, de actos u omisiones cometidos por particulares — por ejemplo, en materia de servicios públicos, independientemente del carácter del prestador. Es el caso de Costa Rica, Reglamento de la Ley de la Defensoría de los Habitantes de la República, artículo 2.

43 GUEDÁN, M; IRÁIZOZ, M. Las Defensorías del Pueblo. Un puente entre la ciudadanía y el Estado en América Latina. Madrid, Ed. Trama, 2006. 
no prever sanciones por violencia de género, por ejemplo, facilita la violación de los derechos de la mujer.

En todo caso, cabe recordar, que en materia de derechos humanos rige el denominado principio pro homine o pro persona, que prescribe que, en caso de duda interpretativa, o en caso de necesidad de elección entre dos normas, debe preferirse aquella que tenga por efecto el reconocimiento más extenso o la mayor protección de los derechos de la persona ${ }^{44}$.

Por tanto, en caso de duda razonable acerca del mandato de una institución nacional de derechos humanos, debe estarse a favor de aquella interpretación que permita incluir situaciones de presunta violación a los derechos humanos dentro de la competencia de la institución, y en contra de aquella que la excluya. Este debería ser el criterio que guíe la interpretación de los límites de sus propias facultades por parte de las instituciones nacionales de derechos humanos - al menos para ser coherentes con la propia razón de su existencia.

La labor de Naciones Unidas en el reconocimiento del papel de los Ombudsman centroamericanos en relación a los derechos económicos, sociales y culturales.

El Comité de Derechos Económicos, Sociales y Culturales de Naciones Unidas $^{45}$ destaca en su Observación General n. ${ }^{\circ} 10$ lo siguiente:

El Comité advierte que las instituciones nacionales desempeñan un papel que puede ser decisivo en la promoción y la garantía de la indivisibilidad y la interdependencia de todos los derechos humanos. Desgraciadamente, con demasiada frecuencia no se ha reconocido a la institución esa función, o ésta ha sido descuidada o considerada de baja prioridad por la institución. Es indispensable, pues, que se preste plena atención a los derechos económicos, sociales y culturales en todas las actividades pertinentes de esas instituciones ${ }^{46}$.

44 Ver S. ALBANESE, "La primacía de la cláusula más favorable a la persona", en Revista La Ley, Buenos Aires, tomo 1996-C-518; M. PINTO, "El principio pro homine. Criterios de hermenéutica y pautas para la regulación de los derechos humanos", en M. ABREGÚ y C. COURTIS (comps.), La aplicación de lo stratados sobre derechos humanos por los tribunales locales, CELSEditores del Puerto, Buenos Aires, 1997, pp. 163-171. Citados por: Christian Courtis. Cuadernos Electrónicos n. 5 Las instituciones nacionales de derechos humanos Derechos Humanos y Democracia.

45 http://www2.ohchr.org/english/bodies/cescr/comments.htm (consulta: 13 julio 2010).

46 Esto no es así en la práctica. Un ejemplo lo ofrece la Procuradora para el Defensa de los derechos humanos en El Salvador en el año 2005, que se queja de la falta de implicación del Estado en la defensa de estos derechos en su Informe Especial presentado al Comité de Derechos Económicos, Sociales y Culturales de la Organización de las Naciones Unidas (ONU), sobre la aplicación del Pacto Internacional de Derechos Económicos, Sociales y Culturales en El Salvador (1995-2005): 247. Esta Procuraduría lamenta, sin embargo, que no se haya transitado en El Salvador hacia la aplicabilidad y funcionalidad efectiva de tales instrumentos y mecanismos, al haberse continuado en la linea de disminuir las capacidades politico-institucionales del Estado respecto a los derechos económicos, sociales y culturales, tanto al interior de sus fronteras nacionales como en relación a otros países e, incluso, respecto a diferentes actores económicos que, en el marco internacional, han cobrado especial relevancia para el respeto y garantía de estos derechos, sobre la base de afectar el ejercicio soberano de las funciones estatales. Todo lo cual ha propiciado 
La lista que sigue da una idea de los tipos de actividades que las instituciones nacionales pueden emprender (y en algunos casos ya han emprendido) en relación con estos derechos: a) el fomento de programas de educación e información destinados a mejorar el conocimiento y la comprensión de los derechos económicos, sociales y culturales, tanto entre la población en general como en determinados grupos, por ejemplo en la administración pública, el poder judicial, el sector privado y el movimiento laboral; b) el minucioso examen de las leyes y las disposiciones administrativas vigentes, así como de los proyectos de ley y otras propuestas, para cerciorarse de que son compatibles con los requisitos estipulados en el Pacto Internacional de Derechos Económicos, Sociales y Culturales; c) la prestación de asesoramiento técnico o la realización de estudios en relación con los derechos económicos, sociales y culturales, inclusive a petición de las autoridades públicas o de otras instancias apropiadas; d) la determinación de criterios nacionales de referencia que permitan medir el grado de cumplimiento de las obligaciones que impone el Pacto; e) la realización de investigaciones y de estudios con vistas a determinar la medida en que se llevan a la práctica determinados derechos económicos, sociales y culturales, bien sea dentro del Estado en general, o en determinadas esferas o en relación con determinadas comunidades particularmente vulnerables; f) la vigilancia de la observancia de derechos específicos que se reconocen en el Pacto y la preparación de informes al respecto dirigidos a las autoridades públicas y a la sociedad civil; y g) el examen de las reclamaciones en que se aleguen violaciones de las normas aplicables en materia de derechos económicos, sociales y culturales dentro del Estado. El Comité encarece a los Estados Partes que velen por que en los mandatos asignados a todas las instituciones nacionales de derechos humanos se preste una atención apropiada a los derechos económicos, sociales y culturales, y les pide que en los informes que presenten al Comité incluyan detalles tanto sobre los mandatos como sobre las principales actividades de esas instituciones.Esta observación general del Comité, que como se sabe está dirigida a interpretar y apoyar la aplicación del PIDESC (ratificado, por otra parte, por los países objeto de nuestro estudio), reconoce la labor que las instituciones nacionales de derechos humanos — entre las que están los Procuradores y Defensores del Pueblo- tienen en relación a estos derechos. Se les insta a vigilar su observancia y a atender reclamaciones fundamentadas en los mismos.

Por otro lado, hay que recordar que la aprobación en diciembre de 2008 del Protocolo Facultativo al Pacto de Derechos Económicos, Sociales y Culturales posibilita a los Estados Parte que lo ratifiquen, el reconocimiento de la competencia del Comité de la ONU de DESC para recibir y evaluar comunicaciones referidas a violaciones de los DESC. Dichas comunicaciones pueden presentarse por parte de individuos o grupo de individuos, una vez agotados

graves reveses en materia de derechos fundamentales como el trabajo, la sindicalización, la seguridad social, la educación y la salud, en clara contravención al principio de progresividad que debería regir el desempeño estatal en estos ámbitos. 
todos los recursos internos en el plazo de un año desde la vulneración del derecho.

Todo lo expuesto refleja una tendencia que se da últimamente que consiste en la reivindicación de la efectividad de los derechos económicos, sociales y culturales ${ }^{47}$. Algunos autores ${ }^{48}$ reclaman un sistema de metas, elementos de referencia o indicadores que debe servir para detectar violaciones por incumplimiento. Este sistema debe estar orientado a medir si se cumplen los contenidos mínimos de las obligaciones y si se producen violaciones fijadas como tales en los esfuerzos interpretativos desarrollados por los organismos competentes en la supervisión y garantia de los derechos sociales - entre los que se encuentran, por ejemplo, los Defensores del Pueblo.

\section{TITLE: The Ombudsman in Central America.}

ABSTRACT: The Ombudsman is created in Sweden in 1809. It is included in theConstitution of Guatemala in 1985, and then it appears in the otherCentral American countries: El Salvador, Costa Rica, Honduras, Nicaragua.This study analyses the creation, composition and functioning of theinstitution in Central America. What is different bere is the fact thatthe Ombudsman has the main mission of guaranteeing buman rights. Finally, we analyse the challenges of the Ombudsman in these countries, with particular attention to bis role in the defense of economical, socialand cultural rights.

Resumen: El Defensor del Pueblo nace en Suecia en 1809. En el ámbito centroamericano la figura se constitucionaliza en 1985 en Guatemala.Posteriormente, va a ir apareciendo en los diversos países objeto de nuestro estudio: El Salvador, Costa Rica, Honduras, Nicaragua.El trabajo que se presenta bace un análisis del surgimiento, composición y funciones de esta institución en Centroamérica. El rasgo común que diferencia a estos países del modelo de Europa occidental es que secentra, no tanto en la función originaria de control de las instituciones del Estado, sino en su misión de proteger los derechos humanos. Se aporta además una reflexión en torno a los retos del Ombudsman en la zona, con especial detenimiento en su papel de defensa de los derechos económicos, sociales y culturales.

KEY WORDS: Central American. Ombudsman. Human rights. Social right. Administrations.

Palabras Claves: América Central. Defensor del Pueblo. Derechos humanos. Derechos sociales. Administración.

Fecha DE RECEPCIÓN: 07.07.2010. FECHA DE ACEPTACión: 28.07.2010.

47 PISARELLO, g. Los derechos sociales y sus garantias: elementos para una reconstrucción. Trotta, Madrid, 2007, pág. 111; ABRAMOVICH, COURTIS, op.cit; PARRA VERA, O. "El sistema interamericano y el enfoque de derechos en las estrategias de desarrollo y erradicación de la pobreza. Algunas líneas de trabajo para las Defensorías del Pueblo". Cuadernos electrónicos n. 5. Derechos Humanos y Democracia.

48 CALVO GARCÍA, M. "La implementación y efectividad de los derechos económicos, sociales y culturales". Cuadernos Democracia y Derechos Humanos. Los derechos sociales como una exigencia de la justicia. Madrid, 2009, pág. 216. El sistema de indicadores lo propone la Comisión Interamericana de Derechos Humanos en materia de indicadores de progreso. Vid. PARRA VERA, O. op. cit., pág. 93. 